\title{
Nutrition knowledge, attitudes and practices of primary school children in Tshwane Metropole, South Africa
}

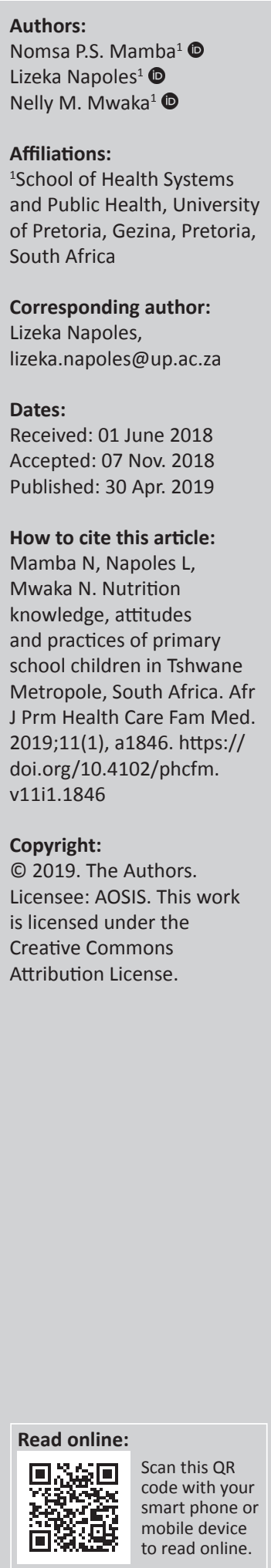

Background: The increasing prevalence of being overweight and obesity in South African school children requires interventions that are evidence based. Nutrition knowledge, attitudes and practices (KAP) studies are thus needed to provide evidence for the planning of interventions that address and prevent nutrition problems in school children.

Aim: The aim of the study on which this article is based was to assess nutrition knowledge, attitudes and practices of grade 4-6 learners from three primary schools in a South African township. The article seeks to highlight the key results of this quantitative study.

Setting: The study took place in three primary schools in Mamelodi township, Pretoria, South Africa.

Methods: Data were collected from grade 4-6 learners using self-administered questionnaires. After coding and collating data using Epi info ${ }^{\text {TM }}$, STATA was then used for analysis. A description of KAP results was carried out using simple descriptive statistics, while the associations were tested using a chi-square test.

Results: Learners displayed inadequate knowledge of a balanced diet (23\%) as well as low knowledge of food groups. With regard to attitudes, the most liked food group was the drinks and snacks $(72.9 \%)$, while the least liked food group was the fruits and vegetables $(8.11 \%)$. With regard to practices, the most frequently consumed food group was the drinks and snacks $(72.6 \%)$, while fruits and vegetables were the least consumed. However, $78.91 \%$ of the learners displayed very good nutrition-related practices, such as making their own breakfast and eating breakfast.

Conclusion: The inadequate knowledge displayed by learners indicates a gap with nutrition education in the curriculum. There is a need to explore innovative and novel approaches to improve nutrition knowledge of school children. Parents also need to be targeted to ensure better outcomes.

Keywords: nutrition knowledge; nutrition attitudes; nutrition practices; nutrition interventions; primary school learners; South Africa.

\section{Background}

Children of primary school age are responsive to health messages and behaviour changes which may be maintained into adolescence and adulthood. ${ }^{1,2}$ For this reason, nutrition interventions targeted at this age group are most likely to have long-term positive effects such as improved nutrition-related practices; reduced nutrition-related problems such as obesity, being overweight, under-nutrition; and nutrition-related chronic diseases. It is essential to assess children's own nutrition knowledge, attitudes and practices (KAP) in order to plan meaningful nutrition interventions that will address gaps as well as factors that influence these aspects.

The development of good nutrition practices is influenced by a number of factors and the knowledge-Attitude-Behaviour (KAB) model provides a framework for the change in nutrition practices. This model suggests that knowledge is a prerequisite for behaviour change. As knowledge increases, attitudes begin to change and, over time, behaviour changes. ${ }^{3}$

An increasing prevalence of overweight and obese children in primary schools has been observed worldwide, including South Africa. Although it is highly prevalent in children from urban areas, this is also an increasing trend in children from the rural areas. ${ }^{4,5,6,7,8}$ According to Reddy et al., the 
national prevalence of overweight children is at $17 \%$ and obesity is at $5 \%$ among South African school children., ${ }^{8,9,10}$ Several factors contribute to being overweight and obese including dietary intake, urbanisation, industrialisation and socioeconomic status of the family. In most cases, dietary intake is directly linked to being overweight and obese among school children ${ }^{7,11,12}$ and, according to Sahota et al., dietary intake is greatly influenced by nutrition KAP.7 Steyn states that poor dietary behaviour, referring to high intake of unhealthy snacks, is a high risk factor for the development of being overweight and obese in South African school children. ${ }^{12}$

On the other hand, under-nutrition is also prevalent in some parts of South Africa. Stunting is the most prevalent form of under-nutrition, followed by being underweight and then wasting. The national prevalence of stunting among school children is at $13 \%$; underweight at $8 \%$ and wasting at $4 \%{ }^{1,9,10}$ While poverty is directly associated with stunting in South Africa, ${ }^{13}$ it has also been reported that parents' inadequate nutrition knowledge, children's poor nutrition practices and infections contribute to the rate of stunting. ${ }^{\text {? }}$

Globally, very little has been published to demonstrate children's own level of nutrition KAP. The focus has been on the knowledge of care givers as well as parents that are responsible for purchasing food and feeding children. ${ }^{14} \mathrm{~A}$ few studies have assessed knowledge and attitudes only ${ }^{15}$ or practices with regard to specific food groups. ${ }^{16}$ In South Africa, one study assessed nutrition knowledge only ${ }^{17}$ and the other nutrition practices only. ${ }^{18}$ Both studies were localised in selected regions of South Africa and cannot be generalised for all other regions, owing to variations in culture.

The assessment of the learners' own nutrition KAP helps the public nutrition practitioners plan appropriate nutrition interventions, to reduce the impact of the stated nutrition problems. The South African government has developed an Integrated School Health Policy (ISHP) which incorporates nutrition education. Within the school health programme, the learners' level of nutrition knowledge as well as their nutrition-related attitudes and practices can be addressed. ${ }^{19}$

Schools provide a suitable setting for influencing children's health and health behaviour and primary schools are particularly suitable for nutrition behaviour change programmes. ${ }^{1,2,12}$

\section{Methods}

\section{Study design}

The study on which this article is based was a cross-sectional descriptive study.

\section{Setting}

The study took place in three primary schools in Mamelodi township, Pretoria, South Africa. The three participating schools form part of the Health Promoting Schools pilot programme facilitated by the University of Pretoria's School of Public Health.

\section{Participants and sampling strategy}

The study population was composed of all learners in grades 4-6 from three primary schools in Mamelodi township of South Africa. A total sample size of 310 learners was obtained from all three schools with a total enrolment of 864, and consisted of all the learners who returned consent forms signed by their parents. A total of 12 questionnaires were disqualified owing to too much missing information, bringing the total number of questionnaires that were analysed to 298 .

\section{Data collection}

A standardised nutrition KAP questionnaire was adopted from the HealthKick programme in South Africa with modifications. The instrument contained simple multiple choice questions with colourful pictures. The instrument was pretested in a primary school within the same location and with a similar setting to those of the target schools. The pretest was to observe factors such as time, the understanding of questions and it was then corrected for errors. The instrument was modified following the findings of the pretest. With regard to nutrition knowledge, learners were asked to identify a picture of a balanced diet and match food groups with their functions in the body. Regarding attitudes, learners were asked to rank their liking of popular foods on a scale of 1 to 5 , where 1 was the least liked and five the most liked. For nutrition practices, learners were asked to rank the consumption of the same foods on a scale of 1 to 5 within the last week of data collection, where 1 was not consumed at all in the last week and 5 consumed more than five times in the last week. In addition, nutrition-related practices were determined by indicating the learners' ability to prepare and eat breakfast, pack their lunch box, their food choices and involvement in physical activities.

\section{Data collection procedure}

Consent was obtained from the three schools, the provincial Department of Education and University of Pretoria Ethics Committee, following successful submission of the protocol. The target population which consisted of learners in grades 4-6 from the three primary schools were all given consent forms to take to their parents. Only learners who returned their signed consent form took part in the study, making a total of 310 learners. The participating learners were then administered with an assent form prior to responding to the questionnaire, which took about $30-45 \mathrm{~min}$ to complete. A standardised KAP questionnaire was self-administered by the learners in the presence of a researcher, a teacher and the local health promoter. The researcher explained the instrument to the learners and where clarification was needed, the teacher and health promoter helped.

The data collection process was conducted over a period of 3 days at the three schools. The principal introduced the research and the researcher to the participating learners who were assembled in one classroom after school. 
The collected data were coded, then entered into Epi info ${ }^{\mathrm{TM}}$ with 12 disqualified entries, and then analysed.

\section{Data analysis}

Data analysis was conducted using STATA. Simple descriptive statistics were used to describe learners' KAP. For the food list used to assess learners' attitudes, new variables were generated to reduce the food list. The generated variables were meant to group the foods into cereals, proteins, fruits, vegetables, drinks and snacks.

\section{Ethical considerations}

Approval for the study was obtained from the Ethics Committee of the University of Pretoria (426/2013). Parents who signed the consent form allowed their children to form part of the study; learners who took part in the study also signed a consent form prior to answering the questionnaire. Permission was also sought from the Gauteng Department of Education as well as from the authorities of the three schools.

\section{Results}

\section{Learners' demographic information}

Learners from three primary schools in Mamelodi township, South Africa, participated in the study. Learners' demographic information was limited to the school, the learners' gender, his or her age and the grade level. Of the total number of participants, 191 were girls and 105 were boys. The highest number of learners (150) were in the middle age group (11-13 years), followed by the lower age group (8-10 years) where there were 141 participants. The age group with the lowest number of participants was the $14-15$ years age group where only five participants took part in the study. Regarding the grade levels, 111 learners participated from grade 4 , followed by 106 from Grade 6 and 78 from Grade 5 .

\section{Description of learners' nutrition knowledge}

Learners were found to have inadequate nutrition knowledge. Only $23.2 \%$ were able to identify picture C, which showed a balanced diet. Regarding the food groups, the most known food group to learners was the body building category with $45.3 \%$ correctly identifying this food group, while the least identified food group was the fibre group at $20 \%$. In most cases, learners did not understand the term fibre. Table 2 shows the percentage of the learners who could correctly identify a balanced diet. Only 69 out of 298 learners $(23.2 \%)$ were able to identify the picture which showed a balanced diet.

\section{Description of learners' attitudes towards nutrition}

When learners were asked to identify foods which they liked, for cereals it was bread with $56.9 \%$, for proteins it was yoghurt with $54.4 \%$, for fruits and vegetables it was oranges with $66.1 \%$ and for drinks and snacks it was biscuits with $72.9 \%$. In general, drinks and snacks was the most liked food group. Table 3 shows the most/least liked foods as well as most/least consumed foods. The most liked foods are the drinks and snacks.

\section{Description of learners' nutrition practices}

Regarding learners' frequent consumption of the same food items; for cereals, bread was the most consumed with $56.3 \%$ and cassava was the least consumed, although in most cases learners did not know what cassava was. The most consumed protein within the last week of data collection was chicken with $50.5 \%$, plant proteins were the least consumed form of protein and some foods such as jugo beans were not known to most learners. The most consumed fruit was an apple with $69.6 \%$ yet the most liked was the orange perhaps owing to the fact that oranges are seasonal fruits. Vegetables were the least consumed food group as a whole. The highest consumed vegetable was onion with $18 \%$, perhaps owing to its regular use during cooking. Drinks and snacks were the most highly consumed food group by learners with sweets scoring $72.6 \%$ as learners had consumed sweets more than five times in the last week of the research. Table 4 shows the most/least consumed foods. The most consumed foods are the drinks and snacks.

\section{Description of learners' nutrition-related practices}

A total of $79.9 \%$ of learners said they do have school lessons on nutrition, while a good percentage (78.9\%) do eat breakfast and they are able to make their own breakfast $(72.7 \%)$. Although $57.8 \%$ said they can make their lunch box, only $41.8 \%$ carry a lunch box to school, this might be because $69.4 \%$ take money to school which they use to buy sweets and snacks.

Learners were further assessed for good choices of fat and $28.8 \%$ of learners said they would not choose meat with skin

TABLE 2: Identification of a balanced diet $(N=298)$.

\begin{tabular}{lcc}
\hline Balance diet & Frequency & Percentage \\
\hline B: some food groups & 152 & 51 \\
A: all food groups & 74 & 24.8 \\
C: all food groups & 69 & 23.2 \\
D: none of the above & 3 & 1 \\
\hline
\end{tabular}

TABLE 1: Learners' demographic information, as captured on the questionnaire.

\begin{tabular}{|c|c|c|c|c|c|c|c|c|}
\hline \multirow[t]{3}{*}{ Schools } & \multicolumn{8}{|c|}{ Frequencies per variable } \\
\hline & \multicolumn{2}{|c|}{ Sex $(\%)$} & \multicolumn{3}{|c|}{ Age group (\%) } & \multicolumn{3}{|c|}{ Grade level (\%) } \\
\hline & $\begin{array}{c}\text { Boys } \\
(N=105)\end{array}$ & $\begin{array}{c}\text { Girls } \\
(N=191)\end{array}$ & $\begin{array}{c}8-10 \\
(N=141)\end{array}$ & $\begin{array}{c}11-13 \\
(N=150)\end{array}$ & $\begin{array}{l}14-15 \\
(N=5)\end{array}$ & $\begin{array}{c}\text { Grade } 4 \\
(N=111)\end{array}$ & $\begin{array}{l}\text { Grade } 5 \\
(N=78) \\
\end{array}$ & $\begin{array}{c}\text { Grade } 6 \\
(N=106)\end{array}$ \\
\hline Mogale Primary School & 31.4 & 5.6 & 39.7 & 30 & 0 & 26.2 & 47.4 & 33 \\
\hline Pula Difate Primary School & 35.3 & 35.1 & 35.5 & 35.3 & 20 & 36 & 37.2 & 32.1 \\
\hline Rethakgetse Primary School & 33.3 & 29.3 & 24.8 & 34.7 & 80 & 37.8 & 15.4 & 34.9 \\
\hline
\end{tabular}


TABLE 3: Learners' nutrition attitudes.

\begin{tabular}{|c|c|c|}
\hline \multirow[t]{2}{*}{ Food items } & \multicolumn{2}{|c|}{ Like } \\
\hline & Frequency & Percentage \\
\hline \multicolumn{3}{|l|}{ Cereals } \\
\hline Bread & 169 & 56.9 \\
\hline Rice & 154 & 51.9 \\
\hline Porridge & 122 & 41.1 \\
\hline Sweet potato & 71 & 24.0 \\
\hline Samp & 54 & 18.3 \\
\hline Cassava & 37 & 12.5 \\
\hline \multicolumn{3}{|l|}{ Proteins } \\
\hline Yoghurt & 161 & 54.4 \\
\hline Milk & 160 & 54.1 \\
\hline Chicken & 159 & 53.9 \\
\hline Fish & 137 & 46.4 \\
\hline Cheese & 119 & 40.2 \\
\hline Peanuts & 108 & 36.5 \\
\hline Beef & 107 & 36.2 \\
\hline Eggs & 103 & 34.9 \\
\hline Bean & 73 & 24.7 \\
\hline Jugo beans & 50 & 16.9 \\
\hline \multicolumn{3}{|c|}{ Fruits and vegetables } \\
\hline Orange & 195 & 66.1 \\
\hline Banana & 186 & 62.8 \\
\hline Apple & 177 & 60.0 \\
\hline Carrots & 54 & 18.3 \\
\hline Cabbage & 36 & 12.2 \\
\hline Onions & 35 & 11.8 \\
\hline Spinach & 28 & 9.46 \\
\hline Tomatoes & 24 & 8.11 \\
\hline \multicolumn{3}{|c|}{ Drinks and snacks } \\
\hline Biscuits & 210 & 72.9 \\
\hline Soft drinks & 209 & 70.9 \\
\hline Cakes & 202 & 68.2 \\
\hline Sweets & 182 & 61.7 \\
\hline Chocolates & 166 & 56.1 \\
\hline Chips & 145 & 49.2 \\
\hline Juice & 119 & 40.2 \\
\hline Water & 76 & 25.7 \\
\hline
\end{tabular}

as a good source of fat, $18.5 \%$ said they would not choose chips and only $29.5 \%$ said they would choose nuts as a good source of fat. Sixty-four per cent said they would choose soft margarine as fat, $51.5 \%$ said they would take avocado as a good source of fat, $31.9 \%$ said they would not take doughnuts as their source of fat and $34.3 \%$ said they would not take pilchards as their source of fat. Table 5 shows the percentage of learners who indicated having a particular nutrition-related practice. Learners displayed good nutritionrelated practices.

Furthermore, learners were asked to identify physical activity that they do and the following were the results:

\section{Description of learners' physical activity}

A total of $87.5 \%$ regard playing games as physical activity, $79.7 \%$ said they have fun when doing physical activity, $72.9 \%$ said they did get encouragement from teachers to do physical activities, while $62.7 \%$ said they also get encouragement from family members; $83.1 \%$ said they do have organised sporting activities in their schools with $72.9 \%$ saying they take part in
TABLE 4: Learners' nutrition practices.

\begin{tabular}{|c|c|c|}
\hline \multirow[t]{2}{*}{ Food items } & \multicolumn{2}{|c|}{ Consumed } \\
\hline & Frequency & Percentage \\
\hline \multicolumn{3}{|l|}{ Cereals } \\
\hline Bread & 166 & 56.3 \\
\hline Rice & 94 & 31.9 \\
\hline Porridge & 83 & 28.1 \\
\hline Samp & 79 & 26.6 \\
\hline Sweet potato & 58 & 19.7 \\
\hline Cassava & 26 & 8.8 \\
\hline \multicolumn{3}{|l|}{ Proteins } \\
\hline Chicken & 149 & 50.5 \\
\hline Milk & 142 & 48.1 \\
\hline Eggs & 139 & 47.0 \\
\hline Yoghurt & 125 & 42.4 \\
\hline Fish & 98 & 33.2 \\
\hline Cheese & 87 & 29.3 \\
\hline Beef & 80 & 27.1 \\
\hline Peanuts & 74 & 25.1 \\
\hline Bean & 63 & 21.4 \\
\hline Jugo beans & 30 & 10.2 \\
\hline \multicolumn{3}{|c|}{ Fruits and vegetables } \\
\hline Apple & 206 & 69.6 \\
\hline Orange & 202 & 68.9 \\
\hline Banana & 160 & 54.2 \\
\hline Onions & 53 & 18.0 \\
\hline Carrots & 51 & 17.4 \\
\hline Tomatoes & 44 & 14.9 \\
\hline Cabbage & 32 & 10.9 \\
\hline Spinach & 31 & 10.5 \\
\hline \multicolumn{3}{|l|}{ Drinks and snacks } \\
\hline Sweets & 215 & 72.6 \\
\hline Biscuits & 205 & 68.8 \\
\hline Chips & 177 & 59.8 \\
\hline Chocolates & 135 & 45.8 \\
\hline Cakes & 128 & 43.4 \\
\hline Juice & 123 & 41.7 \\
\hline Water & 115 & 39.0 \\
\hline Soft drinks & 105 & 35.6 \\
\hline
\end{tabular}

TABLE 5: Learners' nutrition-related practices.

\begin{tabular}{lcc}
\hline Nutrition practice & Frequency & Percentage \\
\hline Have school lessons on nutrition & 235 & 79.9 \\
Eat breakfast & 232 & 78.9 \\
Make breakfast & 214 & 72.8 \\
Take money to school & 204 & 69.4 \\
Make lunch box & 170 & 57.8 \\
Choose what to eat & 134 & 45.6 \\
Carry a lunch box & 123 & 41.8 \\
\hline
\end{tabular}

those sporting activities. A total of $38.6 \%$ of learners said they do not like sports. When learners were asked how much time they spend watching TV or playing TV/computer games a day, $44.4 \%$ said they spend over 1-2 hours per day, $24.8 \%$ said they spend 30-60 minutes per day and 30.9\% said they spend less than $30 \mathrm{~min}$ a day. This is to say that most of the learners spend most of their after school hours watching TV or playing TV/computer games. On the other hand, learners regard engaging in organised sporting activity as the best for their health and $44.1 \%$ said they liked organised sporting activities, yet only $32.9 \%$ said they play outdoor games the most than any other form of physical activity. Table 6 shows 
TABLE 6: Appropriate physical activity.

\begin{tabular}{lcc}
\hline Physical activity & Frequency & Percentage \\
\hline Regard playing games as physical activity & 258 & 87.5 \\
Have organised sporting activity at school & 245 & 83.1 \\
Have fun in physical activity & 235 & 79.7 \\
Encouragement by teacher to do physical activity & 215 & 72.9 \\
Take part in sports at school & 215 & 72.9 \\
Encouragement by family to do physical activity & 185 & 62.7 \\
Do not like sports & 114 & 38.6 \\
\hline
\end{tabular}

the percentage of learners who engage in a particular physical activity. Learners displayed good physical activity although 38.6\% said they do not like sports.

\section{Discussion}

This study assessed the nutrition KAP of grade 4-6 learners from three primary schools in a South African township. In this study, learners' nutrition knowledge was described based on their ability to identify the correct picture which showed a balanced diet and to link the pictures of food groups with their functions. The assessment indicates limited nutrition knowledge. This is consistent with a study conducted by Vijayapushpan et al. in Hyderabad which identified economic transition and urbanisation to be the leading cause of nutrition transition from an African diet to the western diet, and this is attributed to lack of nutrition knowledge. ${ }^{20}$

Vijayapushpan et al. ${ }^{20}$ describe the African diet as one that originated from plant sources and had lots of fibre; in this study, the food group with foods based on plant sources got very low scores. While bread and common fruits like apples, bananas and oranges got high scores, these were significantly lower than the food group comprising sweets, chips and biscuits. This indicates that the most consumed foods were refined foods with very low fibre content.

Oldewage-Theron and $\mathrm{Egal}^{17}$ conducted a study to determine the nutrition knowledge and the nutrition status of primary school children in QwaQwa, a rural town in South Africa. They found that most children had an average knowledge about basic nutrition, although a gap was identified in the role of various food groups in the diet. This same study also identified a gap in learners' knowledge of the functions of food groups in the body and further found that learners have inadequate nutrition knowledge regardless of the high indication of school lessons obtained in nutrition education. ${ }^{17}$

The result of our study on nutrition knowledge is also consistent with the results of a study conducted by Koo et al. on KAP of primary school children towards grains. They found that $70.3 \%$ of children had a low knowledge of the grains. ${ }^{16}$ Vereecken relates children's limited nutrition knowledge to their mothers; she argues that children can only get to know what their mothers give them. ${ }^{21}$

Harris $^{22}$ studied the role of attitudes and barriers on the implementation of a nutrition intervention in primary school children and found that nutrition knowledge depends on the child's age and type of school education and that there was no difference in nutrition knowledge of obese and non-obese children. This was confirmed in a study conducted by Reinehr. ${ }^{23}$,

Secondary findings of our study found that the learners' ability to identify a food group that provides the body with the best energy and a food group that contains proteins is associated with the learners' age. Our study, however, did not look at the type of nutrition education offered to learners and a recommendation in this regard is to be made for further studies.

With regard to nutrition attitudes and practices, our study found that the most liked and frequently consumed food group was 'drinks and snacks' where the learners demonstrated frequent consumption of unhealthy snacks. Apart from the fact that children like sweets, this practice might be perpetuated by the type of food items sold by the vendors at the school gates which was observed during data collection visits. Shariff et al. ${ }^{24}$ and Piscopo ${ }^{25}$ note that food consumption is associated with foods that are available and accessible in the children's environment. The habit of not making a lunch box and carrying money to school could be a contributing factor, as the money learners carry is mainly used to buy energy-dense snacks. This is confirmed in a study conducted by Temple et al. in the Western Cape, South Africa, where they found that children who do not carry a lunch box to school tend to buy unhealthy energy-dense snacks from the shops and vendors around the schools. ${ }^{26}$

With regard to nutrition-related practices, the study found that the majority of learners could make their own breakfast and also had breakfast. A similar study conducted by Lin et al. with elementary children found that only $25 \%$ of these children ate breakfast even though they could make their own breakfast. ${ }^{3}$ The lunch box practice however was contrary to the findings of the study conducted by Abrahams et al. in the Western Cape Province of South Africa, where they found that about $70 \%$ of learners carried lunch boxes to school. The majority of learners in both cases indicated they could prepare their own lunch boxes. ${ }^{3,18}$

Of great interest, however, are the results of our study with regard to food choices, where the majority of learners indicated they would choose 'good' fat sources like nuts and avocado over 'bad' fat sources like chicken skin and potato crisps. This could have been a result of emphasis on choice of fats in the curriculum as well as the approach used. Worsley observes that when procedural knowledge is acquired, it can result in behaviour change. ${ }^{27}$

With regard to physical activity, our study found that a high percentage of learners spend over 1-2 $\mathrm{h}$ a day watching TV or playing TV/computer games. These results confirm the findings of Triches ${ }^{28}$ and Naidoo ${ }^{29}$ who both agreed that $25 \%$ of children in South Africa spend more than $3 \mathrm{~h}$ in 
sedentary behaviour which is a high risk factor for nutritionrelated health problems..$^{28,29,30}$

\section{Limitations}

The main limitation of the study is that the curriculum was not examined before the questionnaire was finalised, to determine the current nutrition content, the type of nutrition education covered and the approaches used for the delivery of nutrition messages.

\section{Conclusion}

The main aim of this research was to assess the nutrition KPA of learners in South African township primary schools. The findings of the study indicate that there is a gap in the learners' nutrition knowledge, especially of the balanced diet and food groups, and this negatively impacts their nutrition attitudes and practices. Learners generally like and consume more energy-dense and less nutritious foods, while their liking for, and consumption of, vegetables is low. The study confirms the theory of the $\mathrm{KAB}$ model that nutrition knowledge is a prerequisite for behaviour change. In this case, limited nutrition knowledge, especially of a balanced diet and the food groups, results in increased liking and consumption of the more energy-dense and less nutrient-dense foods.

The study further demonstrates that the learners' practices are influenced by their exposure to certain foods; learners generally eat what is available at home or at school. The recommendation therefore is to increase learners' exposure to more healthy foods like fruits and vegetables than unhealthy snacks. The exposure should be a joint effort by the school to improve the school environment and homes by providing these. Interventions to regulate foodstuffs that are sold by vendors at schools must be explored as well as those that promote the carrying of lunch boxes by learners from home.

The study highlights the need to strengthen nutrition education in schools, in particular the approaches for its delivery methods. The delivery methods employed to teach nutrition must be appropriate for the impact needed on KAP of the learners. Nutrition education in the curriculum should explore more innovative and novel approaches to improve nutrition knowledge. This could use gamification as one of the methods used to teach certain aspects of nutrition as well as the use of school vegetable gardens as teaching tools.

Interventions should target improving learners' nutrition knowledge which will have a positive impact on their attitudes as well as their practices. Some interventions must target the parents of learners, to play a major role in shaping their children's nutrition KAP at an early age such that they grow with it into adulthood and reduce the risk of noncommunicable diseases. School health policies should be enforced to improve the school environment and make it favourable for learners to make good food choices while at school. The nutrition education curriculum should also be looked at as well, as a mode of delivery.

\section{Acknowledgements Competing interests}

The authors declare that they have no financial or personal relationships that may have inappropriately influenced them in writing this article.

\section{Authors' contributions}

N.P.S.M. was the study leader; she developed the protocol, collected and analysed the data, and wrote the article in partial fulfilment of the requirement for the degree of Masters of Public Health. L.N. was the main supervisor who assisted with study conceptualisation, technical support on subject matter and interpretation of results as well as article writing. N.M.M. was the co-supervisor who assisted with support on mainly methodology and interpretation of results as well as article writing.

\section{References}

1. Kimani-Murage EW, Kahn K, Pettifor JM, Tollman JM, Dunger DB, Gomez-Olive XF. The prevalence of stunting, overweight and obesity, and metabolic disease risk in rural South African children. BMC Public Health. 2010;10(158):1-13. https://doi. org/10.1186/1471-2458-10-158

2. Perez-Rodrigo C, Klepp K, Yngve A, Sjostrom M, Stockley L, Aranceta J. The schoo setting: An opportunity for the implementation of dietary guidelines. Public Health Nutr. 2001;4(2B):717-724. https://doi.org/10.1079/PHN2001162

3. Lin W, Yang H-C, Hang C-M, Pan W-H. Nutrition knowledge, attitudes and behaviour of Taiwanese elementary school children. Asia Pac J Clin Nutr. 2007;16(S2):534-546.

4. Wang Y, Lobstein TIM. Worldwide trends in childhood overweight and obesity. Int J Pediatr Obes. 2006;1:11-25. https://doi.org/10.1080/17477160600586747

5. Dehghan M, Akhtar-danesh N, Merchant AT. Childhood obesity, prevalence and prevention. Nutr J. 2005;4(1):24. https://doi.org/10.1186/1475-2891-4-24

6. Armstrong MEG, Lambert MI, Sharwood KA, Lambert EV. Obesity and overweight in South African primary school children - the Health of the Nation Study. JEMDSA. 2006;11(2):52-63. https://doi.org/10.1080/22201009.2006.10 872144

7. Sahota PS, Rudolph MCJ, Dixey R, Hill AJ, Barth JH, Cade J. Randomised controlled trial of primary school based intervention to reduce risk factors for obesity. BMJ. 2001;323(7320):1029. https://doi.org/10.1136/bmj.323.7320.1029

8. Reddy SP, Resmicow K, James S, et al. Rapid increases in overweight and obesity among South African adolescents: Comparison of data from the South African National Youth Risk Behaviour Survey in 2002 and 2008. Res Pract. 2012;120(2):262-268. https://doi.org/10.2105/AJPH.2011.300222

9. Reddy SP, James S, Sewpaul R, et al. The South African Youth Risk Behaviour Survey 2008. Cape Town: South African Medical Research Council; 2010.

10. Reddy SP, Resmicow K, James S, Kambran NS, Ormadien R, Mbewu AD. Underweight, overweight and obesity among South African adolescents: Results of the 2002 National Youth Risk Behaviour Survey. Public Health Nutr. of the 2002 National Youth Risk Behaviour Survey. Public
2008;12(2):203-207. https://doi.org/10.1017/S1368980008002656

11. Kruger R, Kruger HS, Macintyre UE. The determinants of overweight and obesity among 10 to 15 year-old schoolchildren in the North West Province, South Africa THUSA BANA (Transition and Health during Urbanisation of South Africans; BANA, children) study. Public Health Nutr. 2005;9(3):351-358. https://doi.org/10.1079/ children) study.
PHN2006849

12. Steyn NP, Lambert EV, Parker W, Mchiza Z. A review of school nutrition interventions globally as an evidence base for the development of the Health
Kick programme in the Western Cape, South Africa. S Afr J Clin Nutr. 2009;22(3):145-152. https://doi.org/10.1080/16070658.2009.11734236

13. Steyn NP, Labadarios D, Maunder E, Nel J, Lombard C. Secondary anthropometric data analysis of the national food consumption survey in South Africa: The double burden. Nutrition. 2005;21(1):4-13. https://doi.org/10.1016/j. nut. 2004.09.003

14. Freedman MR, Alvarez KP. Early childhood feeding: Assessing knowledge, attitudes and practices of multi-ethnic child-care providers. J Am Diet Assoc. 2010;110:447-451. https://doi.org/10.1016/j.jada.2009.11.018

15. Edwards JSA, Hartwell HH. Fruit \& vegetables - Attitudes and knowledge of primary school children. J Hum Nutr Dietet. 2002;15:365-374. https://doi.org/ 10.1046/j.1365-277X.2002.00386.x

16. Koo H-C, Poh BK, Ruzita AT. Assessment of knowledge, attitudes and practices towards whole grains amongst children aged 10-11 in Kuala Lumpur, Malaysia. Int J Food Sci Nutr Diet. 2015;4(1):171-177. https://doi.org/10.19070/23263350-1500032 
17. Oldewage-Theron WH, Egal AA. Nutritional knowledge and nutritional status of primary school children in QwaQwa. S Afr J Clin Nutr. 2010;23(3):149-154. primary school children in QwaQwa. S Afr J Clin
https://doi.org/10.1080/16070658.2010.11734329

18. Abrahams Z, de Villiers A, Steyn NP, et al. What's in the lunchbox? Dietary behavior of learners from disadvantaged schools in the Western Cape, South Africa. Public Health Nutr. 2011;14(10):1-7

19. Department of Health. Integrated school health policy. Pretoria: Department of Health; 2012.

20. Vijayapushpam T, Menon KK, Rao DR, Antony GM. A qualitative assessment of nutrition knowledge levels and dietary intake of school children in Hyderabad. Public Health Nutr. 2003;6(7):683-688. https://doi.org/10.1079/PHN2003478

21. Vereecken C. Haerens L, Bourdeauhing ID, Maes L. The relationship between children's home food environment and dietary patterns in childhood and adolescence. Public Health Nutr. 2010;13(10A):1729-1735. https://doi.org/ $10.1017 / \mathrm{S} 1368980010002296$

22. Harris $M$. The role of attitude and barriers on the implementation of a nutrition intervention in primary school children. Doctoral dissertation. Potchefstroom: North-West University; 2012.

23. Reinehr T, Kersting M, Chahda C, Andler W. Nutritional knowledge of obese compared to non-obese children. Nutr Res. 2003;23:645-649. https://doi. org/10.1016/S0271-5317(03)00025-3
24. Mohd Shariff Z, Abusamah B, Paiu L, et al. Nutrition education intervention improves nutrition knowledge, attitude and practices of primary school children: A pilot study. Int Electron J Health Educ. 2008;11:119-132.

25. Piscopo S. Socio-ecological factors influencing food choices and behaviours of Maltese primary schoolchildren. Doctoral dissertation. Birmingham: University of Birmingham; 2004

26. Temple NJ, Steyn NP, Myburgh NG, Nel JH. Food items consumed by students attending schools in different socio-economic areas of Cape Town, South Africa. Nutrition. 2006;22:252-258. https://doi.org/10.1016/j.nut.2005.07.013

27. Worsley A. Nutrition knowledge and food consumption: Can nutrition knowledge change food behaviour? Asia Pac J Clin Nutr. 2002;11(S2):579-585. https://doi. org/10.1046/j.1440-6047.11.supp3.7.x

28. Triches RM, Giugliani ERJ. Obesity, eating habits and nutritional knowledge among school children. Revista de Saúde Pública. 2005;39(4):541-547. https://doi.org/ 10.1590/S0034-89102005000400004

29. Naidoo R, Coopoo Y, Lambert EV, Draper C. The impact of a primary school based nutrition and physical activity intervention on learners in KwaZulu-Natal, South Africa: A pilot study. S Afr J Sports Med 2009:21:10-15. htps://doi.org/10.17159/ 2078-516X/2009/v21i1a301

30. Roberts K, Marvin K. Knowledge and attitudes towards healthy eating and physical activity: What the data tell us. Oxford: National Obesity Observatory; 2011. 